\title{
LIFE CYCLE OF THE COOPERATION NETWORKS ENVIRONMENT: A CASE STUDY OF A CONSTRUCTION COMPANY'S PROJECT OF AN AUTOMOTIVE MOTOR FIRM
}

\author{
Fábio Müller Guerrini, Juliano Borges de Freitas \\ Escola de Engenharia de São Carlos - Universidade de São Paulo, BRAZIL \\ guerrini@sc.usp.br; julianobfreitas@yahoo.com.br
}

\begin{abstract}
A cooperation enterprises network is defined as a group of companies which interact among themselves to exchange competences, therefore, a series of necessities from companies, which would be important in a manufacturing company, and also be in the cooperation network. Through organizational modeling, the manager has a greater view and quicker understanding of the company, which allows the integration among the company's components. An industrial construction project (in this case an automotive motor firm) is characterized by an inter-organizational relationship between companies and an analytical approach based on the life cycle of virtual organization ( as a form of cooperation network) is adequate to identify and model functions, once several resources and competences must be guided by an information flow.
\end{abstract}

\section{INTRODUCTION}

The organization involved in the productive process is under pressure to adopt new concepts concerning global competition (life cycle reduction of products and mass customization) (Wiendahl and Hobis, 1998).

Among these strategies the company's formation network is a practice, which guarantees the survival and competitiveness of the small and medium size companies (Olave and Amato, 2001).

The model of multidirectional networks is feasible for small and medium size companies and licensing model and production outsourcing is under the control of large companies (Castells, 1999).

The organization, viewed from the process perspective (some crossingover external limits of the organization) implicates, unavoidably, in an interfunctional and inter-organizational change (Davenport, 1994), leading to organizational designs that are very different from the ones currently known.

There is an unmistakable tendency that shows that the manufacturing process is not executed by a single company but by many companies collaborating in a specific part of the entire process. However, there is a challenge concerning how an 
industrial manufacturing system will be planned and managed, requiring a Reference Architecture for the flexible cooperation and appropriated protocols and mechanisms. (Camarinha-Matos and Afsarmanesh, 1999b)

This research will define a Reference model to represent the inter-organizational relationship between companies in an automotive motor company construction project; utilizing network companies with an analytical approach in order to understand the problematic situation.

\section{RESEARCH METHOD}

The research method is based on an exploratory case study to identify adequate variables to represent the production process in the design of network companies. The research approach was guided by Soft methodology (Checkland , 1982).

The Soft methodology approach presents the following steps, to create a parallel between the real world and the systemic thought: step 1 (the problematic situation), step 2 (the problematic situation expressed), step 3(key definitions of relevant systems), step 4 (conceptual models), step 5(comparison between conceptual models and expressed problematic situation), step 6(possible desired changes), and step 7(operations to improve the problematic situation) (Checkland , 1982).

According to Soft methodology steps, the stages of this research are represented in Figure 1:

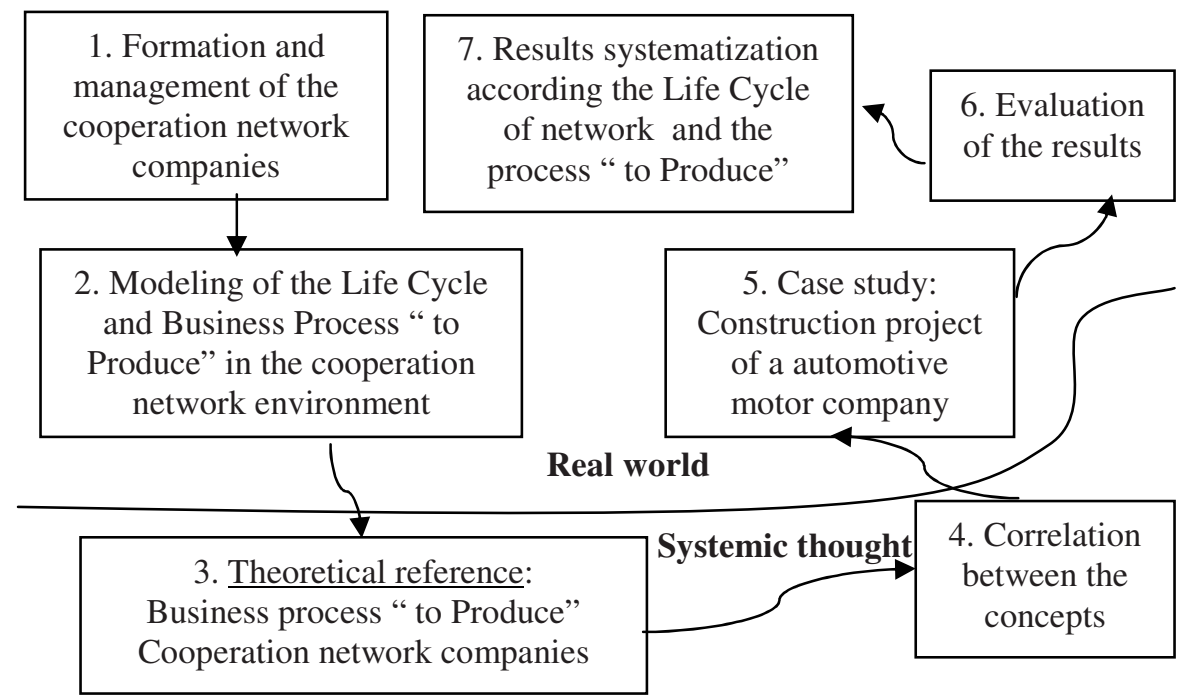

Figure 1: Research steps of this research according Soft methodology

The systematization of inter-organization relationship will be a reference model applying the Enterprise Knowledge Development (EKD) (Bubenko et. al., 2001).

The EKD method is composed of conceptual submodels that examine an organization and its requirements in an inter-related perspective. The submodels are: (1) Objective Model, (2) Actors and Resources Model, (3) Business Rules Model, 
(4) Concepts and Entities Model, (5) Business Process Model and (6) Requirement and Technical Components Model (Bubenko et. al., 2001).

In order to represent the inter-organizational relationship a Business Process Model will be developed. The EKD methodology allows facilitating organization learning and communication, developing a structured business description to the organization analysts can discuss and determinate clearly the objectives and systems requirements and to produce a document (called knowledge repository). The Business Process Model can be utilized to think about the business, discuss changes and information system requirements.

The analytical object "to Produce" is the Business Process of an automotive motor company construction project. The analysis executed at the end of the construction project provides complete information regarding the Life Cycle project. The information was collected by direct observation in the work site of the construction project.

\section{NETWORKS OF COOPERATION AMONG COMPANIES: MORPHOLOGY,} LIFE CYCLE AND BUSINESS PROCESS “TO PRODUCE”

The term network can be understood as a representation model and/or hypothesis to collect, structure and coordinate the relationships between companies with their suppliers and competitors (Katzy et al., 1996), focusing on their essential competences, in order to obtain other parts of chain values of strategic partners (Levin, 1998).

The term network companies usually falls back on a vast range of interorganizational relationships (Nassimbeni, 1998). In this manner there are several expressions referring to the same concept or leading to different approaches Extended Company, Supply Chain Management, Cross Border Enterprise, Agile Manufacture. They cannot be synonymies, but somehow they address similar concepts (Chambers et al., 2000). Other expressions that can be included are: Strategic Alliances and Inter-organizational Networks (Williams, 2002).

The network structures are made up of a Reference Framework that can be applicable towards investigating phenomena characterized by the cooperative relationships density among the agents, which reinforces interdependence among its respective competences and imposes the need for some type of collective coordination of the adopted actions (Britto, 2002).

Although the forms, labels and theoretical contexts of the relationship types of inter-organizational cooperation network differ, three basic characteristics can be identified in the literature (Nassimbeni, 1998):

- The network is made up of two or more companies, at least partly autonomous;

- The legal structure commonly used to administrate is the "estipulated contract";

- Among the parts, dynamic forms of communication and coordination (with more intensity than a person would hope to find in market based changes ) are developed as a form to adapt and synchronize the activity of each part (node) to the activities of the whole system.

The inter-organizational cooperation is stimulated by a growing recognition of the fact that any company or organization has all necessary "capacities" (resources and activities) to reach its goals as well as the goals in the market (Gebrtekidan anf Awuah, 2002). 
The use of the cooperation network concept can be related to some morphologic elements common to this type of structure. There are four generic morphologic elements defining the network structures: nodes, positions, connections and flows (Britto, 2002).

The nodes constitute the basic units of the network companies, identifying the companies inserted in the network as basic units to be investigated. The positions are related to a certain work division that connects the different agents that are seeking to reach certain objectives, involving the integration of operational capacities and the agents' organizational competences (Britto, 2002).

Gebrekidan and Awuah (2002) discuss the relevance of the position (defined as a direct or indirect relationship with the other specific actors) that each actor (company, organization and individuals), creates for itself. The actor's position is established and developed at every moment, by means of process investments. The actor's position in the network warrants him some power regarding certain network activities. Such power, on the other hand, comes from the direct control that actor has over its activities and from the indirect control over the other activities, through the relationship with the other actors.

Within this context, Williams (2002) states that the location of each organization and its position in the network's structure defines benefit possibilities of the organization.

The links among the constituent nodes may be dispersed (number of connections among points is quite limited) enabling the determination of the network density in the structure.

The flows circulating through the connection channels among the nodes are represented by goods (tangible) and information (intangible) (Britto, 2002).

In the manufacturing ambit, the companies have become organized in effective production system frameworks to satisfy market needs, as the virtual manufacture and agile manufacture (Camarinha-Matos and Afsarmenesh, 1999b).

An effective cooperation requires coordination, since independent actors (members of a network) possess different behaviors, priorities and motivations. The coordination is necessary in order to prevent the companies' inefficiency in obtaining a common goal. (Camarinha-Matos and Lima, 1999)

De Toni and Meneghetti (2000) suggest that the crucial question in network companies is mainly coordination, which is accomplished through production planning, when the focus is production or the business process "to Produce".

The connection and coordination forms should be defined balancing two contrasting needs (Nassimbeni, 1998):

- Coordination mechanisms should not be so rigid so that the nodes become robust, leading to a network structure collapse, once such flexibility guarantees the integrated involvement of independent units.

- The coordination mechanisms must assure that the activities of each node are synchronized to the whole system.

The network life cycle segregates the network existence into phases and processes. Despite all phases and process not being representative to the purpose, it is important to present every cycle in order to have sound understanding of the network dynamics. (Goranson, 1999)

The proposal of Camarinha-Matos and Afsarmenesh (1999 a,b) can be a model to other approaches of cooperation networks among companies. It includes the following phases: 
- Creation/ Configuration: is based on partner selection, contract negotiation, definition of access rights and sharing levels, definition and configuration of process connection of the parts. The problem of partner selection should be broken down in two groups: essential partners, responsible for the components, critical services and subsidiary partners, who supply components and services of lesser importance.

- Operation: is based on the modeling of business process to reach common objectives, requiring functionalities such as: request management, distributed and dynamic planning and scheduling, task management. High level coordination tasks. It is observed that in order to give support at the many interaction levels among members of the Virtual Company, the Production planning and control (PPC) is added by a support layer.

- Evolution/ Reconfiguration: is based on exceptional events during the operation phase, as the momentary incapacity of some partner or the need to increase manpower.

- Dissolution: based on the end of the business process and the end of interorganizational relationship.

In a distributed manufacturing environment, the production planning coordinates requests and designates different resources in such cooperative production pertaining to several companies (De Toni and Meneghetti, 2000).

It is recognized that planning and control systems have significant implications for the prosperity of the operations, internally as well as throughout the supply chain. (Kehoe and Boughton, 2001)

There is a growing need for the industrial organizations to explore alternative mechanisms for its operations network management (Kehoe and Boughton, 2001), which can justify the interest in the modeling PPC according to its life cycle network, in order to optimize the productive use of resources, provide production flow, minimize the difficulties and help to keep the efficiency at high levels.

\section{THE CONSTRUCTION PROJECT IN A VIRTUAL ORGANIZATION APPROACH}

A construction work can be analyzed from a virtual organization approach: it is from a business opportunity exploration (the work itself) that companies are employed for task work, specific services and exercising their competence in a particular phase of the construction project.

During the construction project period, the services of the hired companies are complementary to each other and should be appropriately coordinated to rigorously follow the project scheduling. To analyze the virtual organization characteristics that a construction work possesses and its intervening factors, which are characteristics of the sector.

\subsection{Creation/ Configuration}

The Automobile Motor Factory was a special order, where the costumer supplied the characteristics of the industrial plant and needs, without needing to directly participate in the project or in the management of the work. Enterprise B was the 
company that played the "broker" part (searching for partners and management relationships) in the work. The customer met initially with Enterprise B to present project requirements of the factory, and they searched for partner qualifications to form the consortium. It was decided from that meeting that the other three companies, directly contracted by the costumer (Enterprise D, Enterprise A and Enterprise C), would also participate in the business project owing to their specialties.

Therefore, in order to attend such prerogatives, a consortium of four construction companies was formed (Enterprise A, Enterprise B, Enterprise C and Enterprise D), to be responsible for all the stages of the construction project.

At the beginning of the consortium, each company tried to identify individually the competences that the subcontractors would need, also acting as "broker". In the case of the Subcontracted - Sub BCD1 - the company was hired for being the only company in the municipal district, specialized in industrial buildings. The decisive factor for recruiting the company was after a visit to a Compressors factory done by Enterprise B and the client to verify the quality of an oil cooling channel by the Subcontracted Sub BCD1.

For each working contract a competition was performed among the subcontracted companies. The qualifying criterion compared during the judgment was the lowest cost, and the winning criterion of the requests was labor readiness to begin the projects. Each contractor directly hired by the client had autonomy to evaluate proposals for their part in the construction project.

The identification of companies with specific competencies, such as the Subcontracted Sub D2, and all the companies of the industrial assembly were under client responsibility.

The four enterprises (A, B, C and D), in spite of being members of the consortium, were individually hired by the client. This contractual option generated conflicts of interests among the builders because there were no clear distinction of the performance limits and attributions of each company's responsibilities.

\subsection{Operation}

Enterprise A, at first, was the head of the consortium, responsible for the project, planning and management. The factory design was outsourced to other companies, in agreement with the necessary specialty (foundation design, structural design, and hydraulic facilities design among others).

Enterprise B was responsible for executing construction works (concrete structures, metallic structures, masonry and construction in general). The project to execute this was outsourced to Subcontracted Sub BCD1, Subcontracted Sub B2 and Subcontracted Sub B3 (accomplish work); Subcontracted Sub B4 (steel structure), Subcontracted Sub B5 (floor preparation to install machines). In addition, it possessed its own labor force to work the night shift.

Enterprise $\mathrm{C}$ was responsible for the work execution related to road and urban infrastructure of the factory. The implementation was performed by Subcontracted Sub BCD1 (execution work), Subcontracted Sub C2 (network of sewer installation and heliport) and four other subcontracted companies that had a short-term participation in the construction project.

Enterprise D was responsible for implementing work related to sanitation and electric facilities that besides using its own labor in a large part of the construction 
project, outsourced parts of the work. The execution was performed by Subcontracted Sub D2 (fire prevention), Subcontracted Sub D3 (electric assembly) and Subcontracted Sub D4 (cabinet).

At the second stage of the construction project, other companies were directly contracted by the client for specific outdoor illumination (Subcontracted Sub CL1) and industrial assembly.

\subsection{Evolution / Reconfiguration}

The responsible company to manage the joined competences, became Enterprise B, caused by a function distortion that initially belonged to Enterprise A. Enterprise B was responsible for managing the work, demanding deadlines from the subcontracted and other participating companies. One such example that can be pointed out was the placement of the floor in a factory section before Enterprise D had finished the water and sewer systems.

This fact occurred due to the individual contractual form of four companies linked directly to the client. If the contract had been signed in terms of a consortium, all the functions and responsibilities would have been pre-defined before beginning the work. This example evidences the lack of effective mechanisms for the establishment of contracts and subcontracts in the construction sector, which ends up giving leeway to informal situations and empiricism.

The Subcontracted Sub BCD1 was hired initially by Enterprise B to build the two oil cooling channels and the site for the machinery oil filtration. With the service delays caused by the rain period, it was necessary to allocate a larger labor contingent so the implantation of the second oil cooling channel could begin before finalizing the first. Since Subcontracted Sub BCD1 already had eighty-eight employees working on this construction project, and without the possibility for new recruiting, Subcontracted Sub B2 won the competition for the other channel.

During the course of the work, in many situations, subcontracted companies also participated in specific stages of the construction project for specific building services. This way, the reconfiguration of the subcontracted in the consortium followed through according to contingency.

\subsection{Dissolution}

At the end of the construction project, the consortium was dissolved with the withdrawal of Enterprises B and A from the construction site. The two last companies to leave the construction site, which were responsible for the final repairs and works, were Enterprises $\mathrm{C}$ and D. That stage extended for 7 months and showed several performance mistakes, mainly related to the inspection boxes pertaining to the sanitary sewer, where the woodwork that served as form was found under the concrete. The Subcontracted Sub BCD1 was the last construction company to end its activities after 7 months of re-work, when all services ended.

\section{PROPOSAL OF A BUSINESS PROCESS MODEL AND ITS APPLICATION IN THE CONSTRUCTION PROJECT}

Business processes represent the control flow of what happens within the company, 
they materialize management policies, documentation flows, operational processes, manufacture and administrative processes and regulations. And the inter-managerial integration is the concomitant integration of business process of a company to the businesses processes of another, or even sharing parts of business processes by different managerial cooperations. It is inferred that the modeling and the managerial integration are obtained through the modeling and integration of business processes. (Vernadat, 1996)

\subsection{Modelling using EKD methodology}

With that combination, , according to the EKD methodology (Figure 2), a model is presented in which the network Life Cycle is approached, aggregating to it the four morphologic elements proposed by Britto (2002) (nodes, positions, connections and flows), drawn by the business process "to Produce". Such business process is responsible for planning and controlling of the necessary resources with which to convert incomes into products, including PPC activities that enable increasing effectiveness and efficiency.

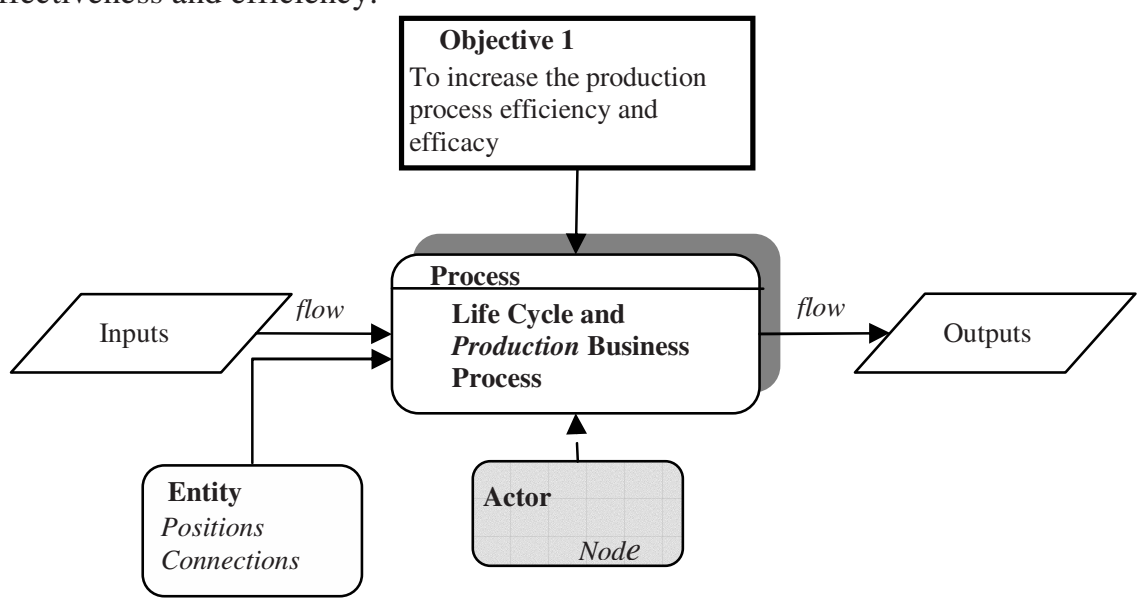

Figure 2: Model proposed according to EKD

\subsection{Case study aplication}

In this way, the application of EKD Business Process Model (Figure 2) to the construction project in question, the model is broadened in order to obtain an outlook of the construction activities according the life cycle and its morphological elements, converging to the model proposed below (Figure 3). In order to understand the model proposed it is pertinent to define the following notation: Sub B - Subcontracted of Enterprise B; Sub C - Subcontracted of Enterprise C; Sub D Subcontracted of Enterprise D and; Sub BCD - Subcontracted of Enterprise B, C and D. 


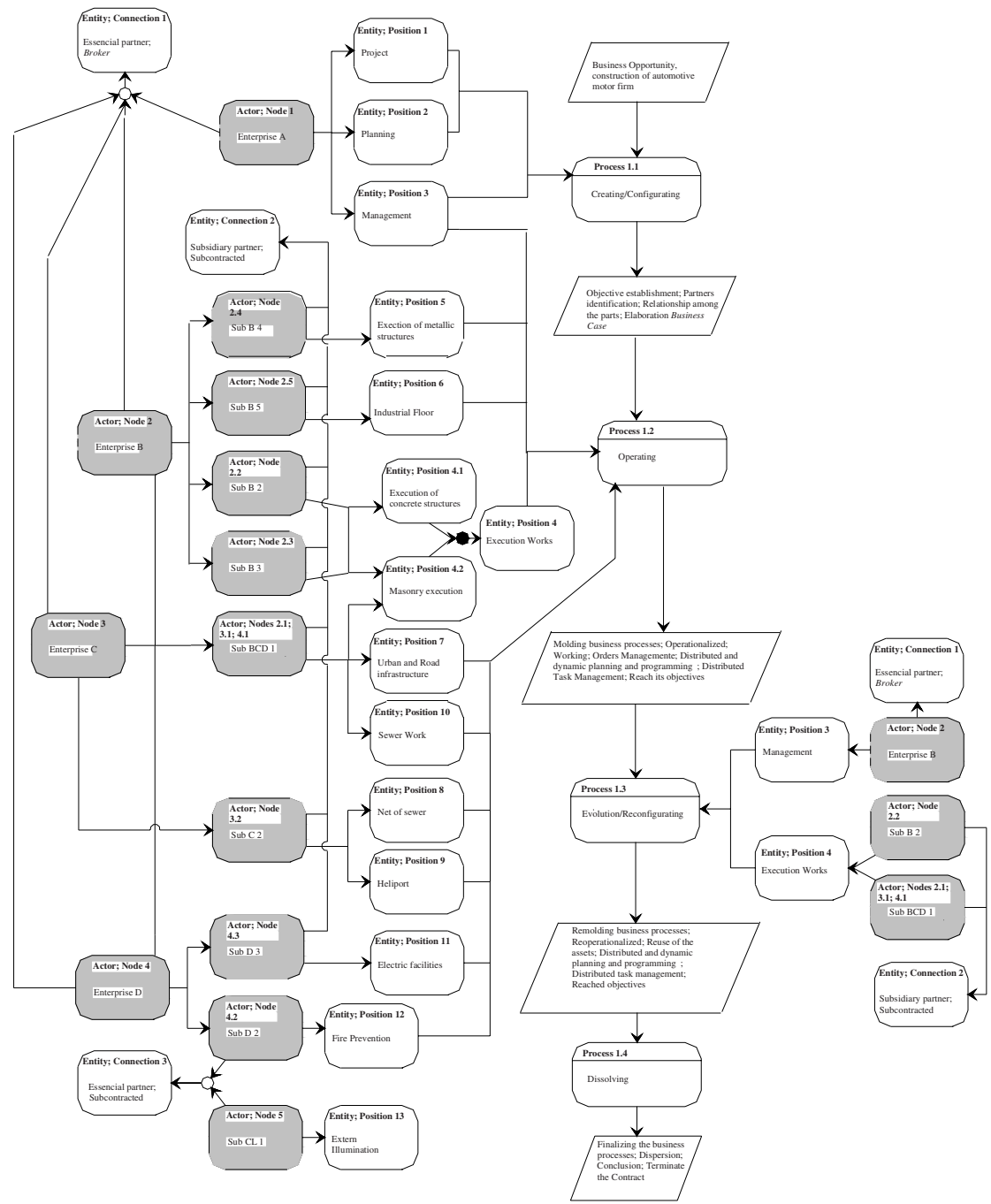

Figure 3: Model proposed according to automotive motor company construction project

The dynamics of the network is linked to the analysis of its life cycle, together with this is the business process "to Produce" throughout the entire network life cycle, according to Camarinha-Matos and Afsarmanesh (1999a, b) (creation/ configuration, operation, evolution/ reconfiguration and dissolution). Thus, the following configuration is given:

- Process 1.1: creation/ configuration

- Process 1.2: operationism

- Process 1.3: evolving/ reconfiguration

- Process 1.4: dissolving

Figure 3 shows essential or subsidized partnership and, acting as a "broker" or subcontracted, forms three different entities and connections (1- essential 
partnership, broker; 2- subsidized partnership, subcontracted; 3- essential partnership, subcontracted).

The Entities; Connections exposed above are composed of the following Actors;Nodes:

- Entity;Connection 1 (essential partnership; broker) is composed of four companies ( Enterprises A, B , C and D) morphologically analyzed like nodes (the Actor;Node 1, 2, 3 and 4, respectively);

- Entity;Connection 2 (subsidized partnership;broker) is composed of subcontracted companies: seven companies that subsidize the enterprise, morphologically analyzed like nodes (the Actor;Node 2.2 - Sub B2, Actor;Node 2.3- Sub B3, Actor;Node 2.4 - Sub B4 and Actor;Node 2.5- Sub B5; Actor;Node 2.1,; 3.1; 4.1- Sub BCD1; Actor;Node 3.2- Sub C2; Actor;Node 4.3- Sub D3);

- Entity;Connection 3 (essential partnership; subcontracted) similar to Entity;Connection 2, it is composed of subcontracted companies: totalling two ( Actor;Node 4.2- Sub D2; Actor;Node 5 - Sub CL1). However the proximity of the two companies with the Customer represents a larger role than only subsidization to the enterprise.

The nodes are related to the positions, along the phases of the network life cycle, according to the configuration below:

\section{Creating/ Configuration (Process 1.1):}

- The Entity; Position 1 (project), Entity; Position 2 (planning) and Entity; Position 3 (project), Entity; Position 3 (management) are related to the Actor; Node 1(Enterprise A).

\section{Operationalism (Process 1.2):}

- Entity; Position 4 (execution services), which can be dismembered into two other Entities; Positions (concrete execution and masonry structures) are related to Actor; Node 2.2 (Sub B2) and Actor; Node (Sub B3);

- Entities; Positions 4.2, 7 and 10 (respectively, execution masonry, road and urban infrastructure, and sanitation) are related to the Actor; Node $2.1 ; 3.1 ; 4.1$ (Sub ABC1);

- Entities; Positions 8 and 9 (respectively, sewer net and heliport) is related to the Actor; Node 3.2 (Sub C2);

- Entity; Position 11 (electric facilities) is related to Actor; Node 4.3 (Sub D3);

- Entity; Position 12 (prevention to fire) is related to Actor; Node 4.2 (Sub D2);

\section{Evolving/ Reconfiguration (Process 1.3):}

- Entity; Position 3 (management) begins to relate to Actor; Node 2 (Enterprise B) and no longer to Actor; Node 1 (Enterprise A);

- After replacement of the company Sub BCD1, due to lack of resources and arrears, Entity; Position 4 (execution of services - related to the oil cooling channels construction and the site to filter the oil machine) begins to relate to Actors; Nodes 2.2; 2.1; 3.1; 4.1 (Sub C2 and Sub BCD1);

In relation to the connections, it can be observed along the life cycle, that the tendency is an approximation to Entities; Positions; once the positions are associated to a certain work division of a construction project, connecting different agents, seeking to reach certain objective and integrating operational capacities. 


\section{CONCLUSION}

The term "network companies" usually recurs to a vast range of inter-organizational relationships, but the "network" type differs in form, labels or theoretical basis. However, they usually refer to similar concepts.

The morphologic elements (nodes, positions, connections and flows) are concepts that attempt to pattern the complex contingent network structure, whose limits are not always well defined and diffused mechanisms. The network life cycle aids in modeling and understanding the inter-organizational relationships. By the business process "to Produce" the managerial politics, operational procedures and manufacture processes are materialized, enabling observation of the activities of PPC, manifesting what the organizational actors do to reach such objectives. It is inferred that the organizational modeling is obtained through modeling of the business process. As synthesis of such reasoning the EKD Business Process Model was proposed in order to represent the construction project of automotive motor company.

In spite of a construction project it is necessary to regulate the mechanisms that supply quantitative and qualitative acting data, thus reducing situations of uncertainty, enabling configuring businesses within a concept of effective virtual organization.

The proposal modeling (Figure 3) supports the specific information of the contractors that the expected results to be accomplished are anticipated, aiding the anticipation of events and the programming of activities, once it enables better understanding of the enterprise.

The modeling facilitates easy visualization of the process "to Produce" in relation to the network life cycle, thus acquiring temporary characteristics.

The model in EKD represent a knowledge base that allows modifications, such as the introduction of new rules in the process or new agents representing the structure, activities, process, information flow and the objective appropriately. The model presented serve to intensify the information exchange among network partners, suggesting the creation of a data base patter, to propitiate consistency of generated data. The presented EKD Business Process Model must be seen as a starting point, since it can be enriched by other models (rules, objective, components and technical requirements), contributing to better visualization and understanding of the approach situation.

\section{REFERENCES}

1. Britto, J. "Cooperação interindustrial e redes de empresas", in Kupfer, D.; Hasenclever, L. (Org's). Economia Industrial: fundamentos teóricos e práticos no Brasil. Rio de Janeiro: Campus, 2002.

2. Bubenko Jr, J. A.; Stirna, J.; Brash, D. "EKD user guide”, Dpt. Of computer and systems sciences. Stockholm". Stockholm: Royal Institute of Technology, 1998.

3. Camarinha-Mattos, L. M.; Afsarmanesh, H. "The virtual enterprise concept". Working Conference on Infrastructure for Virtual Enterprise (PRO-EV'99), 27-28 out. Porto, Portugal 1999a; pp. 3-14.

4. Camarinha-Mattos, L. M.; Afsarmanesh, H. "Tendencies and general requirements for virtual enterprises". Working Conference on Infrastructure for Virtual Enterprise (PRO-EV'99), 27-28 out., Porto, Portugal 1999a; pp. 15-30.

5. Camarinha-Mattos, L. M.; Lima, C. P. "Coordination and configuration requirements in a virtual enterprise”. Working Conference on Infrastructure for Virtual Enterprise (PRO-EV'99), 27-28 out., Porto, Portugal 1999; pp. 49-64. 
6. Castells, M. A sociedade em rede. São Paulo: Paz e Terra, 1999.

7. Chambers, D. B.; Báguena, F. S.; Fernández, M. G. (2000). "Production planning and control information system for the engineering and make to order environment: a virtual enterprise approach". Working Conference on Infrastructure for Virtual Enterprise (PRO-EV'00), 4-6 dec., Florianópolis, Brazil 2000; p. 333-340.

8. Checkland, P. B. Systems thinking, systems practice. New York: John Wiley \& Sons, 1981.

9. Davenport, T. H. Reengenharia de processos: como inovar na empresa através da tecnologia da informação. Rio de Janeiro: Campus, 1994.

10. De Toni, A.; Meneghetti, A. "The production planning process for a network of firms in the textileapparel industry." International Journal of Production Economics, 65; 2000, pp.17-32.

11. Goranson, H. T. "The agile virtual enterprise: cases, metrics, tools". Westport, USA: Quorum Books, 1999.

12. Katzy,B. R.; Schuh, G.; Millarg, K. "Die Virtuelle Fabrik - Produziere im Netzwerk". Tecnische Rundschau Transfer, 43. Swiss: Universität St. Gallen, 1999.

13. Kavakli, V.; Loucopoulos, P. "Goal-driven business process analysis application in electricity deregulation”. Information Systems, v. 24, 3; 1999, pp.187-207.

14. Kehoe, D.; Boughton, N. "Internet based supply chain management: A classification of approaches to manufacturing planning and control". International Journal of Operations \& Production Management, 21, 4; 2001, pp. 516-524.

15. Levin, B. M. "Strategic networks: The emerging business organization and its impact on production costs". International Journal of Production Economics, 56-57; 1998, pp. 397-405.

16. Mizruchi, M.S. \& Galaskiewicz, J. "Networks of Interorganizational Relations". Sociological Methods \& Research. v 22, 11; 1993, pp. 46-70.

17. Nassimbeni, G. "Network structures and co-ordination mechanisms: a taxonomy". International Journal of Operations \& Production Management, v 18, 6; 1998, pp. 538-554.

18. Olave, M. E. L.; Amato, J. "Redes de cooperação produtiva: estratégia de competitividade e sobrevivência para pequenas e médias empresas". Gestão \& Produção, v8, 3; dez 2001, pp.289-303.

19. Rolland, C.; Nurcan, S.; Grosz, G. "A decision making pattern for guiding the enterprise knowledge development process". Information and Software Technology, 42; 2000, pp.313-331.

20. VERNADAT, F. B. (1996). Enterprise Modeling and Integration: principles and applications. New York: Chapman \& Hall, 1996.

21. Vilkamo, T.; Keil, T.. "Strategic technology partnering in high-velocity environments-lessons from a case study". Technovation, 23; 2003, pp. 193-204.

22. Wiendahl, H. P.; Höbig, M. "Balanced production planning and control in production networks". Proceeding of the International Conference of Manufacturing Value-Chain, Troon, Scotland, UK, 1998.

23. Williams, T.. "Cooperation by design: structure and cooperation in interorganizational networks". Journal of Business Research, 5867, p.1-9, Acessível on line 21 nov. 2002.

24. Yin, R. K. Estudo de Caso: planejamento e métodos. Porto Alegre: Bookman Companhia Editorial, 2001. 